\title{
DEGRADABILIDADE IN SITU DE CANA-DE-AÇUCAR ENSILADA COM URÉIA E MILHO EM DIFERENTES PROPORÇÕES
}

\author{
(In situ degradability of the sugar cane ensiled with urea and \\ corn grain in different proportions)
}

\author{
ROSSI JUNIOR, P.'; SCHOGOR, A.L.B. ${ }^{2}$
}

1'Professor Adjunto Departamento de Zootecnia - UFPR. E-mail: parossi@ufpr.br; 2Zootecnista. Curitiba/PR.

\begin{abstract}
RESUMO - O presente trabalho foi realizado no Instituto Agronômico do Paraná (IAPAR), com o objetivo de se avaliar a degradabilidade ruminal in situ da matéria seca (MS) da silagem de cana-de-açúcar (Saccharum officinarum). Os tratamentos testados foram: silagem de cana pura (SC), silagem de cana acrescida de $1 \%$ de uréia (SCU) e silagem de cana acrescida de $1 \%$ de uréia e $2,5 \%$ de milho (SCUM). As médias dos tratamentos foram testadas pelo Teste de Tukey a $5 \%$. O teste de degradabilidade in situ foi realizado em dois búfalos machos, fistulados no rúmen. Os valores observados para degradabilidade potencial e efetiva dos tratamentos testados foram respectivamente: $52,07 \%$ e $38,23 \%$ para SC, $56,40 \%$ e $45,17 \%$ para SCU e $61,93 \%$ e 49,95\% para SCUM. A degradabilidade potencial e efetiva da MS foi superior $(P<0,05)$ para a silagem de cana com $1 \%$ de uréia e 2,5\% de milho com relação a SC e SCU. Dentre as silagens testadas, a que apresentou maior degradabilidade foi a SCUM, devido a inclusão de ingredientes com maior degradação ruminal.
\end{abstract}

Palavras-chave: cana-de-açúcar; degradabilidade efetiva; degradabilidade da matéria seca; degradabilidade potencial.

\begin{abstract}
The present work was carried out at the Agronomy Institute of Parana (IAPAR), to evaluate in situ the ruminal degradability of dry matter (DM) of sugar cane silage (Saccharum officinarum). The treatments tested were: pure sugar cane silage (SC), sugar cane silage with $1 \%$ of urea (SCU) and sugar cane silage with $1 \%$ of urea and $2.5 \%$ of corn grain (SCUM). Tukey test was used to compare treatments means, significance level of $5 \%$. The observed values for potential and effective degradability of the treatments were respectively: $52.07 \%$ and $38.23 \%$ for SC; $56.40 \%$ and $45.17 \%$ for SCU; and $61.93 \%$ and $49.95 \%$ for SCUM. The potential and effective degradability of DM was greater $(P<0.05)$ for sugar cane silage with $1 \%$ of urea and $2.5 \%$ of corn grain than for SC and SCU. Among the tested silages, the one which presented the best results was the SCUM, what may be due to the replacement of sugar cane for ingredients with high ruminal degradation.
\end{abstract}

Key-words: effective degradability; potential degradability; dry matter degradability; sugar cane.

\section{Introdução}

Devido ao crescente emprego da cana-de-açúcar para alimentação de ruminantes, na forma de silagem, a demanda por informações sobre seu real valor e utilização vem sendo requeridas. O uso da cana-deaçúcar como alimento para os animais, no período de escassez das pastagens, só não tem sido mais freqüente porque é pouco estudada para esta finalidade, principalmente quanto à definição de variedades com ciclos de produção diferentes, que sejam mais adequados à produção de forragem e ao seu manejo (FERNANDES et al., 2003).

Tendo em vista as limitações de consumo da canade-açúcar provocado pelas características de sua fração fibrosa e um número relativamente elevado de variedades de cana-de-açúcar, com características melhoradas que visam atender aos interesses da agroindústria, torna-se importante conhecer a qualidade de diferentes variedades de cana-de-açúcar, em termos de conteúdo de fibra e de variáveis da cinética de degradação da FDN, para selecionar aquelas variedades mais divergentes e, posteriormente, confrontá-las em estudos sobre características químicobromatológicas, degradabilidade e testes de desempenho (AZEVEDO et al., 2003).

A cana-de-açúcar, como opção de volumoso, apresenta grande quantidade de carboidratos solúveis, que são rapidamente fermentados no rúmen. Porém, a fibra apresenta baixa degradação ruminal, em parte devido ao baixo teor de proteína presente na cana. Desta forma, para se corrigir essa deficiência é recomendado o uso de elevadas quantidades de uréia (CARMO et al., 2001).

$A$ adição de uréia para ensilagem de materiais forrageiros vem sendo amplamente estudada para conservação e melhoria na qualidade dos mesmos. A uréia, além de aumentar a proteína bruta da silagem, melhora a relação energia/proteína, com reflexo positivo na digestibilidade da MS, permitindo substituir parcialmente os concentrados protéicos nas rações de ruminantes (CASTRO NETO, 2003). Vilela (1984), citado por CASTRO NETO (2003) explicou que o efeito da uréia sobre a digestibilidade da MS pode ser atribuído ao maior suprimento de nitrogênio $(\mathrm{N})$ para os

Endereço para correspondência: SCA/UFPR, Rua dos Funcionários, 1540 - CEP 80035-050, Curitiba-PR. 
microorganismos do rúmen, podendo com isso, refletir positivamente nesse parâmetro de qualidade das silagens.

A utilização da técnica in situ expõe características inerentes a determinado alimento e seu comportamento durante o processo digestivo. Os sistemas mais modernos de dietas para ruminantes levam em consideração a cinética da degradação das diferentes frações dos alimentos, particularmente da proteína e dos carboidratos não estruturais, além de permitir estimar o potencial de crescimento microbiano a partir da fração fermentável (TONANI et al., 2001).

A técnica in situ é considerada precisa, mais prática e menos onerosa comparada a ensaios in vivo. É mais empregada para determinação da degradação protéica no rúmen, embora seu uso também venha sendo destinado a estimativas da degradação da matéria seca e carboidratos (BERCHIELLI et al., 2005).

O objetivo deste trabalho foi analisar por ensaios de degradabilidade in situ, o potencial máximo de degradação dos diferentes tratamentos utilizados, à base de silagem de cana-de-açúcar e a quantidade de material potencialmente degradável e indegradável dos mesmos.

\section{Material e Métodos}

A cana-de-açúcar utilizada foi a da variedade RB 72474, colhida no mês de abril de 2004 e cortadas para ensilagem em um tamanho de partícula de até $10 \mathrm{~mm}$. Os materiais foram ensilados em 12 silos experimentais (3 para cada tratamento) de PVC e lacrados, permanecendo 70 dias. Após esse período foram abertos e colhido material para as análises bromatológica e os testes de degradabilidade.

Os alimentos utilizados foram a silagem de cana pura (SC), silagem de cana pura com adição de $1 \%$ de uréia (SCU) e silagem de cana pura com adição de $1 \%$ de uréia e 2,5\% de milho (Zea mays L.) (SCUM).

Para o teste de degradabilidade, as amostras foram secas em estufa à $65^{\circ} \mathrm{C}$ por 48 horas e moídas em moinho tipo Willey, com peneira de malha de 5 mesh.

O teste de degradabilidade ocorreu no Instituto
Agronômico do Paraná (IAPAR) de Curitiba-Pr, entre o período de 01/06 a 08/06/2004. Foram utilizados dois búfalos machos adultos, fistulados no rúmen.

A técnica de digestibilidade in situ foi realizada de acordo com CAMPOS et al. (2004), somente modificando o modo de incubação dos sacos de nylon que foram colocados dentro de um saco utilizado para lavagem de roupas, o qual facilmente pôde ser fechado e que não apresentou problemas quanto à execução do teste, sendo a corrente colocada dentro deste saco, juntamente com os sacos de nylon, para promover maior peso do mesmo. Cada saco continha aproximadamente 3 gramas de amostra.

Os intervalos utilizados para incubação foram 96,72 , $48,36,24,12,6$ e 0 horas.

Após a retirada dos sacos do rúmen dos animais, estes foram imediatamente imersos em água gelada, para reduzir ao máximo o processo de fermentação do material residual dos sacos, onde permaneceram por 30 minutos. A posterior lavagem dos mesmos foi conjunta, realizada em uma máquina de lavar roupas, adaptada para não danificar os sacos de nylon, até o bom clareamento da água (CAMPOS et al., 2004).

Para o cálculo da degradabilidade potencial das silagens, foi utilizado o modelo proposto por ØRSKOV e McDONALD (1979) em modelo exponencial, para degradação em função do tempo e outra equação baseada no princípio de redução do material durante a incubação.

O delineamento experimental utilizado foi o de blocos inteiramente casualizados, com três tratamentos e quatro repetições (duas por animal), e as análises estatísticas foram realizadas pelo programa SANEST (ZONTA e MACHADO, 1984). O teste de médias utilizado foi o Teste de Tukey, a 5\% de probabilidade.

\section{Resultados e Discussão}

Os resultados da fração solúvel, fração potencialmente degradável, fração indegradável, taxa de degradação, degradabilidade efetiva da matéria seca e degradabilidade potencial da matéria seca estão apresentados na TABELA 1.

TABELA 1 - FRAÇÃO SOLÚVEL (A), FRAÇÃO POTENCIALMENTE DEGRADÁVEL (B), FRAÇÃO INDEGRADÁVEL (C), TAXA DE DEGRADAÇÃO (c\%/h), DEGRADABILIDADE EFETIVA DA MATÉRIA SECA E DEGRADABILIDADE POTENCIAL DA MATÉRIA SECA, DOS DIFERENTES TRATAMENTOS.

\begin{tabular}{cccc}
\hline ANIMAIS & CANA & CANA + URÉIA 1\% & $\begin{array}{c}\text { CANA + URÉIA 1\% + } \\
\text { MILHO 2,5\% }\end{array}$ \\
\hline A (\%) & $23,40^{\mathrm{b}}$ & $33,54^{\mathrm{a}}$ & $35,33^{\mathrm{a}}$ \\
B (\%) & $31,36^{\mathrm{a}}$ & $24,42^{\mathrm{a}}$ & $27,36^{\mathrm{a}}$ \\
C (\%) & $45,94^{\mathrm{a}}$ & $42,02^{\mathrm{ab}}$ & $37,30^{\mathrm{b}}$ \\
C (\%/h) & $3,29^{\mathrm{a}}$ & $3,10^{\mathrm{a}}$ & $3,85^{\mathrm{a}}$ \\
Degradabilidade Efetiva (\%) & $38,23^{\mathrm{b}}$ & $45,17^{\mathrm{a}}$ & $49,95^{\mathrm{a}}$ \\
Degradabilidade Potencial (\%) & $52,07^{\mathrm{c}}$ & $56,40^{\mathrm{b}}$ & $61,93^{\mathrm{a}}$ \\
\hline
\end{tabular}

Médias nas mesmas linhas seguidas de letras diferentes diferem pelo Teste de Tukey $(P<0,05)$.

Archives of Veterinary Science, v.11, n.3, p.15-18, 2006 
Degradabilidade in situ de cana-de-açucar ensilada com uréia e milho em diferentes proporções

A análise estatística mostra que houve diferença significativa $(P<0,05)$ na degradabilidade potencial da matéria seca dos tratamentos testados, sendo que o tratamento SCUM apresentou o maior valor. O aumento do valor da degradabilidade potencial sugere um aumento da participação da parte degradável dos outros elementos, sendo que a uréia é um ingrediente $100 \%$ degradável e o milho segundo PASSINI et al. (2004) pode apresentar degradabilidade efetiva de $41,28 \%$ ( $P$ $<0,05)$ e de $62,27 \%(P<0,02)$.

O mesmo comportamento ocorre com as frações $A$ e $\mathrm{C}$ entre os tratamentos testados. A silagem de cana pura apresentou o resultado mais reduzido da fração A, fração solúvel do alimento, e maiores valores da fração $C$, fração indegradável do alimento $(P<0,05)$, devido à maior participação de fibras indigestíveis, como a lignina, por exemplo. Em contraponto, a silagem com adição de uréia a 1\% e milho a 2,5\% apresentou valores superiores para fração $A$ e mais reduzidos da fração $C$, quando comparados entre si $(P<0,05)$.

Não houve diferença entre a fração insolúvel potencialmente degradável entre os tratamentos $(P<0,05)$.

Os coeficientes de degradação (c, em \%/h), não diferiram estatisticamente entre os tratamentos testados $(P<0,05)$.

Apontando resultados comparativos de testes de degradabilidade in situ utilizando cana in natura, AROEIRA et al. (1993), encontraram valores de degradabilidade efetiva de $63,9 \%$ da MS da cana-deaçúcar e taxa de degradação de 3,2\%/h para dietas contendo $85 \%$ de MS de cana-de-açúcar in natura mais $1 \%$ de uréia e $15 \%$ de suplemento concentrado.

AROEIRA et al. (1995) avaliaram a degradabilidade in situ da dieta a base de cana-de-açúcar in natura e $1 \%$ de uréia suplementadas com farelo de algodão, encontrando valores para degradabilidade efetiva da MS de $51,3 \pm 1,2 \%$ e taxa de degradação de $2,6 \pm 0,1 \% / h$.

LOPES e AROEIRA (1999) observaram uma taxa de degradação in situda MS de uma mistura de cana-de-açúcar in natura e uréia à $2 \%$ do concentrado. Os valores encontrados foram $58,02 \%$ para degradabilidade potencial, $41,94 \%$ para degradabilidade efetiva e uma taxa de degradação deste alimento de 2,21\%/h.

Devido à escassez de dados na literatura sobre degradabilidade in situ, ou até mesmo in vivo da silagem de cana-de-açúcar, abaixo são citados alguns valores de DIVMS da mesma, para serem realizadas as seguintes correlações.

PEDROSO (2003), avaliando a DIVMS de silagens de cana-de-açúcar, obteve valores entre $62,9 \%$ de digestibilidade da amostra no dia zero de ensilagem até $47,2 \%$ de digestibilidade para 90 dias de ensilagem do material. O mesmo autor comenta que o produto sofre uma redução drástica da digestibilidade até o 45을 dia a partir da estocagem do material e, que passado este período, as perdas são mais estáveis.

FREITAS et al. (2006), obteveram valores de DIVMS para seu tratamento controle (silagem de cana sem uso de inoculantes), para cana de 11 meses de idade de
$53,6 \%$ e de cana de 13 meses de idade de $59,1 \%$.

CASTRO NETO (2003) avaliou a DIVMS (em \% da MS) de silagem de cana-de-açúcar com adição de 0,5\% e encontrou $48,55 \%$.

ANDRADE et al. (2001) avaliando a digestibilidade de silagem de cana-de-açúcar tratada com $0,5 \%$ de uréia e acrescida de $0,40,80$ e $120 \mathrm{~kg}$ de rolão-demilho por tonelada de cana picada e ensilada, pelo método de coleta total de excretas em ovinos, encontraram o coeficiente de digestibilidade da matéria seca da silagem acrescida de $0,5 \%$ de uréia um coeficiente de digestibilidade de 53,64\%.

A grande distância entre valores encontrados pelos diversos métodos de avaliação química-bromatológica dos alimentos sugere que maiores testes sejam realizados com o objetivo de se encontrar valores mais acurados da degradabilidade das silagens de cana-deaçúcar. Os valores aqui citados, entre degradabilidade in situ e digestibilidade in vitro das silagens de canade-açúcar, evidenciam a pouca quantidade de trabalhos científicos testando a degradabilidade deste alimento.

\section{Conclusões}

Dentre as silagens testadas, a silagem de cana-deaçúcar com adição de $1 \%$ de uréia e 2,5\% de milho grão apresentou melhor resultado de degradabilidade potencial e efetiva, o que pode ser devido à substituição da cana-de-açúcar por ingredientes com alta degradação ruminal.

\section{Referências}

ANDRADE, J. B.; FERRARI JUNIOR, E.; BRAUN, G. Valor nutritivo da silagem de cana-de-açúcar tratada com uréia e acrescida de rolão-de-milho. Pesquisa Agropecuária Brasileira, v. 36, n. 9, p. 1169-1174, 2001.

AROEIRA, L.J.M.; SILVEIRA, M.I.; LIZIEIRE, R.S.; FIGUEIRA, D.G. Degradabilidade no rúmen e taxa de passagem da cana-de-açúcar mais uréia, do farelo de algodão e do farelo de arroz em novilhos mestiços europeu x zebu. Revista Brasileira de Zootecnia. v. 22, n.4, p. 552-564,1993.

AROEIRA, L.J.M.; LOPES, F.C.F.L; DAYRELL, M.S.; LIZIEIRE, R.S.; TORRES, M.P. Digestibilidade, degradabilidade e taxa de passagem da cana-de-açúcar mais uréia e do farelo de algodão em vacas mestiças holandês x zebu em lactação. Revista Brasileira de Zootecnia. v. 24, n.6, p. 1016-1026,1995.

AZEVEDO, J.A.G.; PEREIRA, J.C.; CARNEIRO, P.C.S.; QUEIROZ, A.C.; BARBOSA, M.H.P.; FERNANDES, A.M.; RENNÓ, F.P. Avaliação da divergência nutricional de variedades de cana-de-açúcar (Saccharum spp.). Revista Brasileira de Zootecnia. v. 32, n.6, p. 1431-1442, 2003.

BERCHIELLI, T.T.; OLIVEIRA, S.G.; GARCIA, A.V. Aplicação de técnicas para estudos de ingestão, composição da dieta e digestibilidade. Archives of Veterinary Science. v. 10, n. 2, p. 29-40, 2005.

Archives of Veterinary Science, v.11, n.3, p.15-18, 2006 
CAMPOS, F. P.; NUSSIO, M. B.; NUSSIO, L.G. Métodos de Análise de Alimentos. Piracicaba : FEALQ. p.111116. 2004.

CARMO, C.A.; BERCHIELLI, T.T.; ANDRADE, P.; ZEOLA, N.M.B.L. Degradabilidade da matéria seca e fibra em detergente neutro da cana-de-açúcar (Saccharum spp) com diferentes fontes de proteína. Revista Brasileira de Zootecnia, v.30, n.6, p. 21262133, 2001 (Suplemento).

CASTRO NETO, A.G. Avaliação de silagens de canade-açúcar submetidas a diferentes tratamentos. Belo Horizonte, 2003, 53p. Dissertação de Mestrado. Universidade Federal de Minas Gerais.

FERNANDES, A.M.; QUEIROZ, A.C.; PEREIRA, J.C. LANA, R. P.; BARBOSA, M. H. P.; FONSECA, D. M.; DETMANN, E. CABRAL, L. S.; PEREIRA, E. S. VITTORI, A. Composição químico-bromatologica de variedads de cana-de-açúcar (Saccharum spp I.) com diferentes ciclos de produção (precoce e intermediário) em três idades de corte. Revista Brasileira de Zootecnia. v.32, n.4, p. 977-985, 2003.

FREITAS, A.W.P.; PEREIRA, J.C.; ROCHA, F.C.; DETMANN, E.; BARBOSA, M.H.P.; RIBEIRO, M.D.; COSTA, M.G. Avaliação da divergência nutricional de genótipos de cana-de-açúcar (Saccharum spp.). Revista Brasileira de Zootecnia. v.35, n.1, p. 229236, 2006.
LOPES, F.C.F.; AROEIRA, L.J.M. Degrabilidade do capimelefante (Pennisetum purpereum Schum) e da cana-deaçúcar (Saccharum officinarum, L.) mais uréia no rúmen de vacas Holandês x Zebu em lactação. Arquivo Brasileiro de Medicina Veterinária e Zootecnia, v.51, p.383-386, 1999.

ØRSKOV, E.R., McDONALD, J. The estimation of protein degradability in the rumen from incubation measurements weighted according to rate of passage. Journal of Agricultural Science, v.92, n. 2, p. 499-503, 1979.

PASSINI, R.; BORGATTI, L. M. O.; FERREIRA, F. A. Degradabilidade no rúmen bovino de grãos de milho processados de diferentes formas. Pesquisa Agropecuária Brasileira, v. 39, n. 3, p. 271-276, 2004.

PEDROSO, A.F. Aditivos químicos e microbianos no controle de perdas e na qualidade de silagem de canade-açúcar (Saccharum officinarum L.). Piracicaba, 2003. 120 p. Tese de Doutorado. Escola Superior de Agricultura Luiz de Queiroz.

TONANI, F.L.; RUGGIERI, A.C.; QUEIROZ, A.C.; ANDRADE, P. Degradabilidade ruminal in situ da matéria seca e da fibra em detergente neutro em silagens de híbridos de sorgo colhidos em diferentes épocas. Arquivo Brasileiro de Medicina Veterinária e Zootecnia, v. 23, n. 1, p. 100-104, 2001.

ZONTA, E.P.; MACHADO, A.A. SANEST - Sistema de Análise para Microcomputadores. Pelotas, RS. Universidade Federal de Pelotas, 1984.

Recebido para publicação: $23 / 08 / 2006$ Aprovado: $05 / 11 / 2006$ 